\title{
DIFFUSION APPROXIMATION \\ FOR GI/G/1 QUEUEING SYSTEMS \\ WITH FINITE CAPACITY : I-THE FIRST OVERFLOW TIME
}

\author{
Toshikazu Kimura \\ Katsuhisa Ohno \\ and \\ Hisashi Mine \\ Kyoto University
}

(Received May 27, 1978)

\begin{abstract}
A GI/G/1 queueing system with finite capacity is studied. The first overflow time, which means the time when the number of customers first exceeds the capacity, is analyzed by diffusion approximation. Approximate expressions for the distribution and moments of the first overflow time are derived explicitly. These results are modified so as to be more accurate for an $\mathrm{M} / \mathrm{G} / 1$ system or a system with small capacity. Further these results are applied to the analysis of the maximum number of customers up to time $t$ in a GI/G/1 system with infinite capacity. Finally, the accuracy of the diffusion approximations is examined numerically by using the analytical results for a GI/M/1 system.
\end{abstract}

\section{Introduction}

Consider a $G I / G / I$ queueing system with finite capacity for which it is assumed that the maximum number of customers allowed in the system is equal to $N-1$; that is, the total number of waiting places is $N-2$. Further assume that interarrival and service times of customers are independent and identically distributed (i.i.d.) random variables with distribution functions (d.f.s) $A$ and $H$, respectively. Denote the (mean, variance) of the d.f.s $A$ and $H$ by $\left(\frac{1}{\lambda}, \sigma_{a}^{2}\right)$ and $\left(\frac{1}{\mu}, \sigma_{s}^{2}\right)$, respectively.

Such a system has been studied as a model for many practical service facilities. In the design of a computer system, for example, one of the important problems is how much capacity is required for a buffer memory. This is because, if its capacity is too little, then overflows of customers (jobs) occur frequently in heavy traffic and the performance of the system deteriorates rapidly. On the other hand, if its capacity is too great; then 
most buffer memories remain unused. Thus detailed information on the jobs behaviour should be obtained.

For an $M / G / 1$ and a $G I / M / 1$ systems with finite capacity, stationary queue length distributions have been studied by Keilson [10]. The $M / G / 1$ system has also been studied by Cohen $[2,3]$. An $E_{k} / G / 1$ system with finite capacity has been analyzed by using the phase technique by Truslove $[18,19]$ and its asymptotic behaviour has been studied by Hokstad [9]. An $M / M / 1$ system with finite capacity has been discussed adequately by Finch [6].

In this paper, the overflows of customers in the $G I / G / 1$ queueing system with finite capacity are dealt with under the heavy traffic condition. Overflows occurring as customers arrive to find waiting places fully occupied, are characteristic events of queueing system with finite capacity. Let $Q(t)$ denote the number of customers in the system at time $t$. The sample path of the process $Q(t)$ are defined as continuous from the left. Then, the first overflow time, defined by

$$
T(i, N) \equiv \inf \{t \geqq 0 \mid Q(t)=N, Q(0)=i\} \quad N \geqq 2,0 \leqq i \leqq N-1,
$$

represents the time at which the number of customers first exceeds the capacity. Note that the first overflow time is invariant with work-conserving service disciplines $[11,16]$. Let $F_{i N}(t)$ and $f_{i N}(s)$ (Re $s \geqq 0$ ) denote the d.f. of $T(i, N)$ and its Laplace-Stieltjes transform (L.S.T.), respectively. That is,

$$
f_{i N}(s) \equiv \int_{0}^{\infty} e^{-s t} d F_{i N}(t), \quad \operatorname{Re} s \geqq 0 .
$$

Saaty [14] has referred to the first overflow time in the analysis of a birth and death process. His result, which corresponds to the first overflow time for the $M / M / 1$ system, can be rewritten as

$$
f_{i N}(s)=\frac{\lambda\left(\alpha_{+}^{i+1}-\alpha_{-}^{i+1}\right)-\mu\left(\alpha_{+}^{i}-\alpha_{-}^{i}\right)}{\lambda\left(\alpha_{+}^{N+1}-\alpha_{-}^{N+1}\right)-\mu\left(\alpha_{+}^{N}-\alpha_{-}^{N}\right)},
$$

where

$$
\alpha_{ \pm} \equiv \frac{(\lambda+\mu+s) \pm \sqrt{(\lambda+\mu+s)^{2}-4 \lambda \mu}}{2 \lambda} .
$$

Consequently the mean first overflow time is given by

$$
E[T(i, N)]= \begin{cases}\frac{N-i}{\lambda-\mu}+\frac{\lambda}{(\lambda-\mu)^{2}}\left\{\left(\frac{\mu}{\lambda}\right)^{N+1}-\left(\frac{\mu}{\lambda}\right)^{i+1}\right\}, & \text { if } \lambda \neq \mu \\ \frac{(N-i)(N+i+1)}{2 \lambda}, & \text { if } \lambda=\mu .\end{cases}
$$


In this paper, the first overflow time defined by (1.1) is analyzed by using diffusion model approximation. That is, the d.f. and moments of the first overflow time are derived from the first passage time of a diffusion process approximating $Q(t)$. These results lead to some asymptotic properties of the first overflow time, which are relevant to fluid approximation. Further these results are applied to the analysis of the maximum number of customers in another system with infinite capacity, and yield Laplace transforms (L.T.S) of the d.F. and the mean maximum number of customers. Finally, the accuracy of the diffusion approximations is examined numerically by using the analytical results for a $G I / M / 1$ system.

\section{Preliminaries for Diffusion Approximation}

The basic arguement used in diffusion approximation is as follows:

Let $\{x(t) ; t \geq 0\}$ denote a homogeneous diffusion process and $p\left(x, t \mid x_{0}\right)$ its probability density function (p.d.f.), i.e.,

$$
p\left(x, t \mid x_{0}\right) d x=P\left\{x \leq x(t)<x+d x \mid x(0)=x_{0}\right\} .
$$

Then, $p\left(x, t \mid x_{0}\right)$ satisfies the following Kolmogorov equations:

$$
\frac{\partial p}{\partial t}=\frac{1}{2} a \frac{\partial^{2} p}{\partial x^{2}}-b \frac{\partial p}{\partial x}
$$

and

$$
\frac{\partial p}{\partial t}=\frac{1}{2} a \frac{\partial^{2} p}{\partial x_{0}^{2}}+b \frac{\partial p}{\partial x_{0}} .
$$

They are called the forward (Fokker-Planck) equation, and the backward equation, respectively. The diffusion parameters $a$ and $b$ denote the infinitesmal variance and the mean of the process, respectively. Diffusion approximation means to approximate queue characteristics of general queueing systems through the Kolmogorov equations. It is shown in [12] that diffusion approximation is efficient under the heavy traffic condition. The diffusion parameters $a$ and $b$ are determined by the elementary renewal theorem from asymptotic properties of the characteristic to be approximated [8]. For example, they are given by, for the queue length,

$$
\begin{aligned}
& a=\lambda^{3} \sigma_{a}^{2}+\mu^{3} \sigma_{s}^{2} \\
& b=\lambda-\mu .
\end{aligned}
$$

Upon equations (2.2) and (2.3), the initial condition

$$
p\left(x, 0 \mid x_{0}\right)=\delta\left(x-x_{0}\right)
$$


is imposed, where $\delta(\cdot)$ denotes the Dirac's delta function. Furthermore, appropriate boundary conditions are necessary in order to keep the process in the desired region. A reflecting barrier is used as a boundary condition at $x=0$ for the queue length. The boundary condition for the reflecting barrier is given by, for (2.2),

$$
\frac{1}{2} \alpha \frac{\partial p}{\partial x}-\left.b p\right|_{x=0}=0,
$$

and for (2.3), given by

$$
\left.\frac{\partial p}{\partial x_{0}}\right|_{x_{0}=0}=0 \text {. }
$$

The reflecting barrier is effective under the heavy traffic condition [12].

\section{Distribution and Moments of the First Overflow Time}

Starting from the backward equation (2.3), we shall derive both the p.d.f. and d.f. of the first overflow time. Following Newe11 [12], we assume the heavy traffic condition. Since the heavy traffic condition means that the traffic intensity $\rho \equiv \lambda / \mu$ is close to unity, this condition is appropriate to the overflows because these are rare events when $\rho$ is relatively small. Let $x(t)$ be the diffusion process which approximates the queue length $Q(t)$. Define ${ }^{T} d\left(x_{0}, N\right)$ by

$$
T_{d}\left(x_{0}, N\right) \equiv \inf \left\{t \geqq 0 \mid x(t)=N, x(0)=x_{0}\right\},
$$

$$
0 \leq x_{0}<N
$$

where for notational convenience, the initial value $i$ is setted as $x_{0}$. From the arguement in section 2, it follows that $p\left(x, t \mid x_{0}\right)$ defined by (2.1) satisfies the Kolmogorov's backward equation (2.3) with the initial condition (2.5), where the diffusion parameters are given by (2.4). Moreover, since the process $x(t)$ is restricted within the interval $[0, N]$ and terminates when it reaches at $x=N$, the reflecting barrier is placed at the origin and an absorbing barrier is placed at $x=N$.

Let $F\left(t \mid x_{0}, N\right)$ and $f\left(s \mid x_{0}, N\right)$ denote the d.f. of $T_{d}\left(x_{0}, N\right)$ and its L.S.T. . Then

$$
\begin{aligned}
\int_{0}^{N} p\left(x, t \mid x_{0}\right) d x & =P\left\{T_{d}\left(x_{0}, N\right)>t\right\} \\
& =1-F\left(t \mid x_{0}, N\right) .
\end{aligned}
$$

From (2.3), (2.5) and (3.2), it is easily shown that $f\left(s \mid x_{0}, N\right)$ satisfies the following ordinary differential equation [4, p.230]: for $0<x_{0}<N$, 
(3.3) $\quad \frac{1}{2} a \frac{d^{2} f}{d x_{0}^{2}}+b \frac{d f}{d x_{0}}=s f$.

The boundary conditions at $x_{0}=0$ and $x_{0}=N$ are:

$$
\left.\frac{d f}{d x_{0}}\right|_{x_{0}=0}=0
$$

and

$$
f(s \mid N, N)=1 .
$$

From (3.3) through (3.5), a caluculation similar to [4, p.233] leads to

$$
f\left(s \mid x_{0}, N\right)=\exp \left\{\frac{b}{a}\left(N-x_{0}\right)\right\} \frac{b \sinh c x_{0}+a c \cosh c x_{0}}{b \sinh c N+a c \cosh c N} \text {, }
$$

where

$$
c \equiv \sqrt{b^{2}+2 a s} / a \text {. }
$$

Clearly, the L.T. $F^{*}\left(s \mid x_{0}, N\right)$ of the probability that the overflows occur within $t$ is given by

$$
F^{*}\left(s \mid x_{0}, N\right)=\frac{1}{s} f\left(s \mid x_{0}, N\right) \text {. }
$$

Next, we shall derive the moments of $T_{d}\left(x_{0}, N\right)$. For $n=0,1, \ldots$, let $m_{n}\left(x_{0}, N\right)$ denote the $n$-th moment of $T_{d}\left(x_{0}, N\right)$, where for $n=0$ we assume $m_{0}\left(x_{0}, N\right)=1$. Usually, $m_{n}\left(x_{0}, N\right)$ can be obtained by

$$
m_{n}\left(x_{0}, N\right)=\left.(-1)^{n} \frac{d^{n}}{d s^{n}} f\left(s \mid x_{0}, N\right)\right|_{s=0} .
$$

However, this is very difficult because $f\left(s \mid x_{0}, N\right)$ given by (3.6) has a complicated form. Therefore, we shall adopt another method [4, p.232]. That is, since $f\left(s \mid x_{0}, N\right)$ is the moment generating function of $T_{d}\left(x_{0}, N\right)$, we have

$$
f\left(s \mid x_{0}, N\right)=\sum_{n=0}^{\infty} m_{n}\left(x_{0}, N\right) \frac{(-s)^{n}}{n !} .
$$

Substituting (3.10) in (3.3) and equating coefficients of powers of $s$, we obtain for $n=1,2, \ldots$,

$$
\frac{1}{2} a \frac{d^{2} m_{n}}{d x_{0}^{2}}+b \frac{d m_{n}}{d x_{0}}=-n m_{n-1} \text {. }
$$

Similarly we can deduce the boundary conditions for (3.11) from (3.4) and (3.5). That is, for $n=1,2, \ldots$,

$$
\left.\frac{d m_{n}}{d x_{0}}\right|_{x_{0}=0}=0
$$


and

$$
m_{n}(N, N)=0
$$

For $n=1,2$, solving (3.11) with (3.12) and (3.13), we obtain the mean and the variance of $T_{d}\left(x_{0}, N\right)$ as follows:

$$
\begin{aligned}
& E\left[T_{d}\left(x_{0}, N\right)\right] \equiv m_{1}\left(x_{0}, N\right) \\
= & \begin{array}{ll}
\frac{1}{b}\left(N-x_{0}\right)+\frac{a}{2 b^{2}}\left\{\exp (-2 b N / a)-\exp \left(-2 b x_{0} / a\right)\right\}, & \text { if } b \neq 0 \\
\frac{1}{a}\left(N^{2}-x_{0}^{2}\right), & \text { if } b=0,
\end{array}
\end{aligned}
$$

and for the second moment of ${ }^{T}{ }_{d}\left(x_{0}, N\right)$,

$$
\begin{aligned}
& m_{2}\left(x_{0}, N\right) \\
& \begin{array}{ll}
\frac{1}{b^{2}}\left(N-x_{0}\right)^{2}+\frac{a^{2}}{b^{3}}\left[\left(N-x_{0}\right)+4 \exp (-2 b N / a)\right. \\
\left.-\left(N+x_{0}\right)\left\{\exp (-2 b N / a)+\exp \left(-2 b x_{0} / a\right)\right\}\right] \\
+\frac{a^{2}}{2 b^{4}}\{2+\exp (-2 b N / a)\}\left\{\exp (-2 b N / a)-\exp \left(-2 b x_{0} / a\right)\right\}, \\
\frac{1}{3 a^{2}}\left(N^{2}-x_{0}^{2}\right)\left(5 N^{2}-x_{0}^{2}\right), & \text { if } b \neq 0
\end{array}
\end{aligned}
$$

The derivation of the above results is shown in Appendix. From (3.14) and (3.15), the variance of $T_{d}\left(x_{0}, N\right)$ is given by

$$
\begin{aligned}
& \mathrm{V}\left[T_{d^{2}}\left(x_{0}, N\right)\right] \equiv m_{2}\left(x_{0}, N\right)-\left\{m_{1}\left(x_{0}, N\right)\right\}^{2} \\
& =\left\{\begin{array}{cc}
\frac{a^{2}}{4 b^{4}}\left\{\exp (-2 b N / a)+\exp \left(-2 b x_{0} / a\right)+4\right\}\left\{\exp (-2 b N / a)-\exp \left(-2 b x_{0} / a\right)\right\} \\
\quad+\frac{-}{b^{3}}\left[\left(N-x_{0}\right)+2\left\{N \exp (-2 b N / a)-x_{0} \exp \left(-2 b x_{0} / a\right)\right\}\right], \\
\frac{2}{3 a^{2}}\left(N^{4}-x_{0}^{4}\right), & \text { if } b \neq 0
\end{array}\right.
\end{aligned}
$$

Remark 3.1. Sweet and Hardin [17] have derived the p.d.f. which corresponds to that of $T_{d}\left(x_{0}, N\right)$ by solving the Kolmogorov's forward equation (2.2) with similar boundary conditions. However, because their solution has an infinite series form, it seems impossible to derive the moments of $T_{d}\left(x_{0}, N\right)$ in simple forms. 


\section{Modifications of the Boundary Condition}

In the preceding section we have considered the reflecting barrier as the boundary condition at the origin. However, if $\rho<1$, then discontinuity of the path $Q(t)$ at the origin quite effects the solution, and hence (3.14) seems to be slightly underestimated from the true value. That is, if the process $Q(t)$ reaches to the boundary $x=0$, the process remains at $x=0$ for a residual interarrival time. Then a new customer arrives at the system, the process jumps to $x=1$ and thereafter the process starts from scratch. Under the assumption that the arrival process is the recurrent process, it may be difficult to obtain the distribution of the sojourn time at $x=0$.

However, if the arrival process is a Poisson process, then it is known that the sojourn time is exponentially distributed with parameter $\lambda$. Feller [5] has called this process an elementary return process.

Taking account of the sojourn time at the origin, we consider two modifications of the boundary condition. The first one is a heuristic modification of changing the location of the reflecting barrier. The second one is a modification of using the elementary return process. It follows from the definition of the elementary return process that the latter is appropriate for the $M / G / I$ system. In the following the process $Q(t)$ having the reflecting barrier at the origin is called the reflecting barrier process. Moreover, when $A$ denotes a characteristic for the reflecting barrier process, then $\hat{A}$ and $A$ denote that for the modified reflecting barrier process and the elementary return process, respectively.

\subsection{Modified reflecting barrier process}

Since it may be difficult in general to obtain the distribution of the sojourn time at the origin, it is assumed that the sojourn times have the same distribution as the stationary residual life [13] of the interarrival time. Under this assumption the mean sojourn time is given by $\left(\lambda^{2} \sigma_{a}^{2}+1\right) / 2 \lambda$. Let us consider a modification of changing the location of the reflecting barrier at $x=0$ in accordance with this time. It should be noted that this modification is equivalent to changing the location of the absorbing barrier at $x=N$, since the diffusion process is spartially homogeneous. Place the reflecting barrier at $x=-\Delta$, or equivalent1y, place the absorbing barrier at $x=N+\Delta$, where

$$
\Delta \equiv \frac{\lambda^{2} \sigma_{a}^{2}+1}{4} \text {. }
$$


Then, the relations $\hat{f}\left(s \mid x_{0}, N\right)=f\left(s \mid x_{0}+\Delta, N+\Delta\right), \quad \mathrm{E}\left[\hat{T}_{d}\left(x_{0}, N\right)\right]=\mathrm{E}\left[T_{d}\left(x_{0}+\Delta, N+\Delta\right)\right]$ and $\mathrm{V}\left[\hat{T}_{d}\left(x_{0}, N\right)\right]=\mathrm{V}\left[T_{d}\left(x_{0}+\Delta, N+\Delta\right)\right]$ imp1y that

$$
\begin{aligned}
& \hat{f}\left(s \mid x_{0}, N\right)=\exp \left\{\frac{b}{a}\left(N-x_{0}\right)\right\} \frac{b \sinh c\left(x_{0}+\Delta\right)+a \cosh c\left(x_{0}+\Delta\right)}{b \sinh c(N+\Delta)+a \cosh c(N+\Delta)}, \\
& E\left[\hat{T}_{d}\left(x_{0}, N\right)\right] \\
= & \left\{\begin{array}{rr}
\frac{1}{b}\left(N-x_{0}\right)+\frac{a}{2 b^{2}} \exp (-2 b \Delta / a)\left\{\exp (-2 b N / a)-\exp \left(-2 b x_{0} / a\right)\right\}, \\
\frac{1}{a}\left(N^{2}-x_{0}^{2}\right)+\frac{2 \Delta}{a}\left(N-x_{0}\right), & \text { if } b \neq 0
\end{array}\right.
\end{aligned}
$$

and

$(4.4)$

$$
\begin{aligned}
& \mathrm{V}\left[\hat{T}_{d}\left(x_{0}, N\right)\right] \\
& =\left\{\begin{array}{cc}
\frac{a^{2}}{4 b^{4}} \exp (-2 b \Delta / a)\left[\exp \{-2 b(N+\Delta) / a\}+\exp \left\{-2 b\left(x_{0}+\Delta\right) / a\right\}+4\right] \\
\left.\cdot \exp (-2 b N / a)-\exp \left(-2 b x_{0} / a\right)\right\}+\frac{a}{b^{3}}\left(\left(N-x_{0}\right)\right. \\
\left.+2\left[(N+\Delta) \exp \{-2 b(N+\Delta) / a\}-\left(x_{0}+\Delta\right) \exp \left\{-2 b\left(x_{0}+\Delta\right) / a\right\}\right]\right), \\
\frac{2}{3 a^{2}}\left\{(N+\Delta)^{4}-\left(x_{0}+\Delta\right)^{4}\right\}, & \text { if } b \neq 0
\end{array}\right.
\end{aligned}
$$

Further, it follows from (1.5) that for $\rho=1$, the value of $\mathrm{E}\left[\hat{\mathrm{T}}_{d}\left(x_{0}, N\right)\right]$ for the $M / M / 1$ system agrees with the exact one. It will be shown in section 6 that the modified solutions are fairly accurate.

\subsection{Elementary return process}

Using the elementary return process, we shall precisely describe the boundary condition at $x=0$ for the $M / G / 1$ system. That is, for equation. (3.3), we replace the boundary condition (3.4) by

$$
\tilde{f}(s \mid 0, N)=\frac{\lambda}{\lambda+s} \tilde{f}(s \mid 1, N),
$$

(see [4, p.232]). Solving (3.3) with the boundary conditions (4.5) and (3.5), we obtain

$$
\tilde{f}\left(s \mid x_{0}, N\right)=\exp \left\{\frac{b}{a}\left(N-x_{0}\right)\right\} \frac{(\lambda+s) \sinh c x_{0}-\lambda \exp (-b / a) \sinh c\left(x_{0}-1\right)}{(\lambda+s) \sinh c N-\lambda \exp (-b / a) \sinh c(N-1)},
$$

By the method described in Section 3 , the mean of $\tilde{T}_{d}\left(x_{0}, N\right)$ can be derived as follows: for $n=1,2, \ldots$, the substitution of (3.10) into (4.5) leads to

$$
\tilde{m}_{n}(0, N)=\tilde{m}_{n}(1, N)+\frac{n}{\lambda} \tilde{m}_{n-1}(0, N) \text {. }
$$


This equation represents the boundary condition of (3.11) for the elementary return at $x=0$. In particular, for $n=1$ we have

$$
\tilde{m}_{1}(0, N)=\tilde{m}_{1}(1, N)+\frac{1}{\lambda} \text {. }
$$

It seems that this expression suggests an average behaviour of the elementary return process. Solving (3.11) for $n=1$ with the boundary conditions (4.8) and (3.13), we obtain

$$
\begin{aligned}
& \mathrm{E}\left[\tilde{T}_{d}\left(x_{0}, N\right)\right] \equiv \tilde{m}_{1}\left(x_{0}, N\right) \\
= & \left\{\begin{array}{lc}
\frac{1}{b}\left(N-x_{0}\right)+\frac{1}{\rho b\{1-\exp (-2 b / a)\}}\{\exp (-2 b N / a) & \left.\exp \left(-2 b x_{0} / a\right)\right\}, \\
\frac{1}{a}\left(N^{2}-x_{0}^{2}\right)+\left(\frac{1}{\lambda}-\frac{1}{a}\right)\left(N-x_{0}\right), & \text { if } b \neq 0
\end{array}\right.
\end{aligned}
$$

The derivation of this equation is shown in Appendix.

Remark 4.1. It is easily shown that under the heavy traffic condition (3.14), (4.3) and (4.9) are equivalent except for the term o( $\left.\frac{1}{\lambda}\right)$. This is because the sojourn time at $x=0$ decreases to zero as the value of increases, and because the process hardly depends on the boundary conditions at $x=0$ under the heavy traffic.

Remark 4.2. Fluid approximation [11] is a rough approximation which disregards both the randomness of the arrival and the service processes and the discreteness of the path $Q(t)$. In fluid approximation, we regard cumulative numbers of arrivals and departures as fluids which pour into a reservoir and pour out from it, respectively. Therefore, if $b \leqq 0$, then the amount of fluid in the reservoir never exceeds its capacity, whereas if $b>0$, then the capacity will be exceed within a finite time since the amount of fluid increases by $b$ per unit time. Let $T_{f}\left(x_{0}, N\right)$ be the fluid approximation of $T\left(x_{0}, N\right)$. Then from the above arguement, we obtain

$$
T_{f}\left(x_{0}, N\right)= \begin{cases}\frac{1}{b}(N-x), & \text { if } b>0 \\ +\infty & \text { if } b \leqq 0 .\end{cases}
$$

Note that for $b>0, T_{f}\left(x_{0}, N\right)$ corresponds to the first term of (3.14), $(4.3)$ and $(4.9)$.

Remark 4.3. From (3.14), (4.3) and (4.9), for $b>0$, we have

$$
\text { (4.11) } \quad \lim _{a \downarrow 0} E\left[T_{d}\left(x_{0}, N\right)\right]=\lim _{a \downarrow 0} E\left[\hat{T}_{d}\left(x_{0}, N\right)\right]=\lim _{a \downarrow 0} E\left[\tilde{T}_{d}\left(x_{0}, N\right)\right]=T_{f}\left(x_{0}, N\right) .
$$

Under the heavy traffic condition, we have 


$$
\begin{aligned}
E\left[T_{d}\left(x_{0}, N\right)\right] & =T_{f}\left(x_{0}, N\right)+o\left(\frac{1}{\lambda}\right), \\
E\left[\hat{T}_{d}\left(x_{0}, N\right)\right] & =T_{f}\left(x_{0}, N\right)+o\left(\frac{1}{\lambda}\right), \\
& \left.\tilde{\sim} \tilde{T}_{d}\left(x_{0}, N\right)\right]=T_{f}\left(x_{0}, N\right)+o\left(\frac{1}{\lambda}\right) .
\end{aligned}
$$

Furthermore,

and

$$
\begin{aligned}
& \mathrm{V}\left[T_{d}\left(x_{0}, N\right)\right]=\text { o }\left(\frac{1}{\lambda}\right), \\
& \left.\hat{\mathrm{T}}_{d}\left(x_{0}, N\right)\right]=\mathrm{o}\left(\frac{1}{\lambda}\right) .
\end{aligned}
$$

These relations imply that the solution by diffusion approximation converges to that by fluid approximation as $\lambda \rightarrow+\infty$.

\section{Application of the First Overflow Time}

As an application of the first overflow time, we shall investigate a transient behaviour of the naximum number of customers in a system with infinite capacity. Suppose that the arrival and the service processes of this system are identical with the model discussed so far. The maximum number of customers up to time $t$ is defined as

$$
M\left(t \mid x_{0}\right) \equiv \sup _{0 \leq \tau \leq t}\left\{Q(\tau) \mid Q(0)=x_{0}\right\}
$$

Let $M_{d}\left(t \mid x_{0}\right)$ denote the diffusion approximation of $M\left(t \mid x_{0}\right)$. Then we can derive the d.f. of $M_{d}\left(t \mid x_{0}\right)$ from the following relation [13],

$$
\left\{M_{d}\left(t \mid x_{0}\right) \leqq y\right\}=\left\{T_{d}\left(x_{0}, y\right) \geqq t\right\}
$$

Hence,

$$
\begin{aligned}
L\left(y, t \mid x_{0}\right) & \equiv P\left\{M_{d}\left(t \mid x_{0}\right) \leqq y\right\} \\
& =1-F\left(t \mid x_{0}, y\right) .
\end{aligned}
$$

For $\operatorname{Re} s \geq 0$, let $L^{*}\left(y, s \mid x_{0}\right)$ denote the L.T. of $L\left(y, t \mid x_{0}\right)$. From (5.3), we obtain

$$
L^{*}\left(y, s \mid x_{0}\right)=\frac{1}{s}\left\{1-f\left(s \mid x_{0}, y\right)\right\} .
$$

Moreover, the mean maximum number of customers is given by

$$
\begin{aligned}
\mathrm{E}\left[M_{d}\left(t \mid x_{0}\right)\right] & \equiv \int_{x_{0}}^{\infty} y d_{y} L\left(y, t \mid x_{0}\right) \\
& =x_{0} U(t)+\int_{x_{0}}^{\infty} F\left(t \mid x_{0}, y\right) d y,
\end{aligned}
$$


where

$$
U(t) \equiv \begin{cases}1, & \text { if } t>0 \\ 0, & \text { if } t \leq 0 .\end{cases}
$$

Combining (3.8) and (5.5) yields

$$
\int_{0}^{\infty} e^{-s t} E\left[M_{d}\left(t \mid x_{0}\right)\right] d t=\frac{1}{s}\left\{x_{0}+\int_{x_{0}}^{\infty} f\left(s \mid x_{0}, y\right) d y\right\} .
$$

Remark 5.1. In (5.4), the reflecting barrier process is used. However, if the arrival process is a Poisson process, then $f$ had better been replaced by $\tilde{f}$. Further for small $N, f$ may be replaced by $\hat{f}$.

Remark 5.2. Because of the complicated form of $f\left(s \mid x_{0}, y\right)$, to integrate the right hand side of (5.6) is very difficult, but if $b=0$ for the reflecting barrier process, then the integration can be executed. That is, from (3.6) and (5.6), for $b=0$ we obtain

$$
\int_{0}^{\infty} e^{-s t} E\left[M_{d}\left(t \mid x_{0}\right)\right] d t=\frac{1}{s}\left[x_{0}+\frac{1}{c}\left\{\pi-2 \arctan \left(e^{c x_{0}}\right)\right\} \cosh c x_{0}\right] .
$$

Moreover, if $x_{0}=0$ in (5.7), then the analytical inversion of the transform leads to

$$
\mathrm{E}\left[M_{d}(t \mid 0)\right]=\sqrt{\frac{a \pi t}{2}} .
$$

Therefore it can be observed that if the number of customers is equal to zero at $t=0$ and the traffic intensity $\rho=1$, the mean maximum number of customers up to time $t$ is proportional to the square root of $t$.

\section{Comparisons with the Analytical Results}

\subsection{Analytical results for a $G I / M / 1$ system}

It is quite difficult to analyze the first overflow time for the $G I / G / I$ queueing system. However, for the case that the service time distribution is negative exponential, that is, for the GI/M/1 system, the first overflow time can be investigated by using the regenerative property. Denote the $i$-th arrival epoch to the system by $t_{i}(i=1,2, \ldots)$. Assume that the interarrival times $a_{i} \equiv t_{i+1}-t_{i} \quad(i=1,2, \ldots)$ are $i . i . d$. random variables with d.f. A. It should be noted that the distribution of $a_{0} \equiv t_{1}$ does not necessarily agree with $A$. Since the initial time $t=0$ may not be an arrival epoch, it is assumed to keep generality that the distribution of $a_{0}$ is $A_{0}$. For this system, the process $Q(t)$ is regenerative with respect to 
the delayed renewal process $\left\{N_{t} ; t \geqq 0\right\}$ with

$$
\begin{aligned}
N_{t} & \equiv \max \left\{n \mid t_{n}<t\right\}, \quad \text { for } t>0 \\
N_{0} & \equiv 0 .
\end{aligned}
$$

Since the service times are negative exponentially distributed, it follows that for $i=0,1, \ldots, N-2, n \geqq 1$,

$$
\begin{aligned}
q_{i j}(t) & \equiv P\left\{Q\left(t_{n}+t\right)=j \mid t_{n}+t<t_{n+1}, Q\left(t_{n}\right)=i\right\} \\
& = \begin{cases}\int_{0}^{t} \frac{(\mu x)^{i}}{i !} e^{-\mu x} \mu d x, & \text { for } j=0 \\
\frac{(\mu t)^{i+1-j}}{(i+1-j) !} e^{-\mu t}, & \text { for } j=1, \ldots, i+1 \\
0, & \text { for } j=i+2, \ldots,\end{cases}
\end{aligned}
$$

(see, e.g., $[2, \mathrm{p} .204]$ ) and that for $i=0,1, \ldots, N-1$,

$$
\begin{aligned}
p_{i j}(t) & \equiv P\left\{Q(t)=j \mid t<t_{1}, Q(0)=i\right\} \\
& = \begin{cases}\delta_{0 j}, & \text { for } i=0 \\
q_{i-1, j}(t), & \text { for } i \neq 0,\end{cases}
\end{aligned}
$$

where $\delta$ denotes the Kronecker's delta.

Since the overflows occur at the arrival epoch and $Q(t)$ is leftcontinuous, if $Q\left(t_{n}\right)=N-1$, then $T(\cdot, N)=t_{n}$. Furthermore, the value of $Q(t)$ never increases between two successive arrivals or during $\left(0, t_{1}\right)$. Hence, the d.f. of the first overflow time can be derived from that of a entrance time to $N-1$ on the epochs just before arrivals. For the sake of convenience, let $Q_{n}=Q\left(t_{n}\right)$. Define the d.f. of the entrance time to $N-1$ from the first arrival epoch as

$$
\Phi_{j, N-1}^{(1)}(t) \equiv P\left\{Q_{2}=N-1, t_{2}<t \mid Q_{1}=j\right\},
$$

$$
\begin{aligned}
& \Phi_{j, N-1}^{(n)}(t) \equiv P\left\{Q_{n+1}=N-1, t_{n+1}<t, Q_{h} \neq N-1, h=2, \ldots, n \mid\right. \\
& \left.Q_{1}=j\right\} \quad \text { for } n \geqq 2 \text {, }
\end{aligned}
$$

and

$$
\Phi_{j, N-1}(t) \equiv \sum_{n=1}^{\infty} \Phi_{j, N-1}^{(n)}(t) .
$$

It is verified from the renewal theoretic consideration that there is a relation between $F_{i N}(t)$ and $\Phi_{j, N-1}(t)$ such that for $i=0,1, \ldots, N-1$,

$$
F_{i N}(t)=\int_{0}^{t} p_{i, N-1}(u) d A_{0}(u)+\sum_{j=0}^{N-2} \int_{0}^{t} p_{i j}(u) \Phi_{j, N-1}(t-u) d A_{0}(u) .
$$


Taking the L.S.T. of both sides of $(6.6)$ yields

$$
f_{i N N}(s)=\pi_{i, N-1}(s)+\sum_{j=0}^{N-2} \pi_{i j}(s) \phi_{j, N-1}(s),
$$

where

$$
\pi_{i j}(s) \equiv \int_{0}^{\infty} e^{-s t} p_{i j}(t) d A_{0}(t)
$$

and

$$
\phi_{j, N-1}(s) \equiv \int_{0}^{\infty} e^{-s t} d \Phi{ }_{j, N-1}(t) .
$$

For $\Phi_{j, N-1}^{(n)}(t), j=0,1, \ldots, N-2$, the following integral relations hold.

$$
\Phi_{j, N-1}^{(1)}(t)=\int_{0}^{t} q_{j, N-1}(u) d A(u),
$$

and for $n \geqq 2$,

$$
\Phi_{j, N-1}^{(n)}(t)=\sum_{k=0}^{N-2} \int_{0}^{t} q_{j k}(u) \Phi_{k, N-1}^{(n-1)}(t-u) d A(u) .
$$

Combining $(6.5),(6.10)$ and $(6.11)$ leads to

$$
\Phi_{j, N-1}(t)=\int_{0}^{t} q_{j, N-1}(u) d A(u)+\sum_{k=0}^{N-2} \int_{0}^{t} q_{j k}(u) \Phi_{k, N-1}(t-u) d A(u) .
$$

Taking the L.S.T. of $(6.12)$ yields

$$
\phi_{j, N-1}(s)=\alpha_{j, N-1}(s)+\sum_{k=0}^{N-2} \alpha_{j k}(s) \phi_{k, N-1}(s),
$$

where

$$
\alpha_{j k}(s) \equiv \int_{0}^{\infty} e^{-s t} q_{j k}(t) d A(t) .
$$

Consequently, the above results can be summarized as follows:

Proposition 1. Let $\left\{\phi_{j}(s) ; j=0,1, \ldots, N-2\right\}$ be a solution of a system of linear equations

$$
\phi_{i}(s)=\alpha_{i, N-1}(s)+\sum_{j=0}^{N-2} \alpha_{i j}(s) \phi_{j}(s) \quad i=0,1, \ldots, N-2
$$

with $\alpha_{i j}(s)$ given by (6.14). Then, the L.S.T. of the d.f. of the first overflow time for the $G I / M / 1$ system is given by

$$
f_{i N}(s)=\pi_{i, N-1}(s)+\sum_{j=0}^{N-2} \pi_{i j}(s) \phi_{j}(s),
$$

where $\pi_{i j}(s)$ are given by (6.8).

$$
\text { Denote, for } i=0,1, \ldots, N-1, j=0,1, \ldots, N-2 \text {, }
$$

$$
\bar{\alpha}_{i j} \equiv-\left.\frac{d}{d s} \alpha_{i j}(s)\right|_{s=0}
$$


and

$$
\bar{\pi}_{i j} \equiv-\left.\frac{d}{d s} \pi_{i j}(s)\right|_{s=0} \text {. }
$$

Then, from Proposition 1, the next proposition holds.

Proposition 2. Let $\left\{\bar{\phi}_{j}, 2 \bar{\phi}_{j} ; j=0,1, \ldots, N-2\right\}$ be a solution of two systems of linear equations

$$
\bar{\phi}_{i}=\frac{1}{\lambda}+\sum_{j=0}^{N-2} \alpha_{i j}(0) \bar{\phi}_{j}
$$

and

$$
\begin{aligned}
{ }_{2} \bar{\phi}_{i}=\left\{\left(\sigma_{\alpha}^{2}+\frac{1}{\lambda^{2}}\right)+2 \sum_{j=0}^{N-2} \bar{\alpha}_{i j} \bar{\phi}_{j}\right\}+\sum_{j=0}^{N-2} \alpha_{i j}(0)_{2} \bar{\phi}_{j}, & \\
& \text { for } i=0,1, \ldots, N-2 .
\end{aligned}
$$

Then, the first and second moments of the first overflow time for the GI/M/I system are given by

$$
\mathrm{E}[T(i, N)]=v_{1}+\sum_{j=0}^{n /-2} \pi_{i j}(0) \bar{\phi}_{j}
$$

and

$$
\mathrm{E}\left[\{T(i, N)\}^{2}\right]=v_{2}+2 \sum_{j=0}^{N-2} \pi_{i j} \bar{\phi}_{j}+\sum_{j=0}^{N-2} \pi_{i j}(0)_{2} \bar{\phi}_{j},
$$

respectively, where $v_{i} \equiv \int_{0}^{\infty} c^{i} d A_{0}(x), \quad i=1,2$.

Proof: Differenciating $(6.7)$ and $(6.13)$ with respect to $s$ and using the relations

and

$$
\begin{aligned}
& \sum_{j=0}^{N-1} \alpha_{i j}(s)=\int_{0}^{\infty} e^{-s t} d A(t) \\
& \sum_{j=0}^{N-1} \pi_{i j}(s)=\int_{0}^{\infty} e^{-s t} d A_{0}(t),
\end{aligned}
$$

we obtain the desired results immediately.

Note that the above results are also applied to the analysis of the maxi-mum number of customers in the system by the same method as in Section 5.

Final forms corresponding to (5.4) and (5.6) are respectively

$$
\int_{0}^{\infty} e^{-s t} P\{M(t \mid i) \leqq j\} d t=\frac{1}{s}\left\{1-f_{i j}(s)\right\},
$$

and

$$
\int_{0}^{\infty} e^{-s t} E[M(t \mid i)] d t=\frac{1}{s}\left\{i+\sum_{i=j+1}^{\infty} f_{i j}(s)\right\} .
$$

Remark 6.1. Let $\alpha(s)$ and $I$ be the $(N-1) \times(N-1)$ matrices of elements $\alpha_{i j}(s)$ and $\delta_{i j}$, respectively. Then, it is well known that for $\operatorname{Re} s \geqq 0$, the matrix $I-\alpha(s)$ is nonsingular. Hence, each system of linear equations 
$(6.13),(6.17)$ and $(6.18)$ has a unique solution.

Remark 6.2. If the arrival distribution $A$ is the Erlang distribution with phase $k$, i.e.,

$$
A(t)=\int_{0}^{t} \frac{(\lambda k)^{k} x^{k-1}}{(k-1) !} e^{-\lambda k x} d x,
$$

then the explicit form of $\alpha_{i j}$ (s) can be caluculated as

$$
\alpha_{i j}(s)=\left\{\begin{array}{lc}
\left(\frac{\lambda}{s+\lambda k}\right)^{k}-\sum_{j=1}^{N-1} \alpha_{i j}(s), & \text { for } j=0 \\
\left(\begin{array}{c}
i-j+k \\
k-1
\end{array}\right)\left(\frac{\mu}{s+\mu+\lambda k}\right)^{i-j+1}\left(\frac{\lambda k}{s+\mu+\lambda k}\right)^{k}, \\
0, & \text { for } j=1, \ldots, i+1 \\
& \text { for } j=i+2, \ldots .
\end{array}\right.
$$

Moreover, if $A_{0}=A$, then we have

$$
\pi_{i j}(s)= \begin{cases}\delta_{j 0}\left(\frac{\lambda k}{s+\lambda k}\right)^{k}, & \text { for } i=0 \\ \alpha_{i-1, j}(s), & \text { for } i \neq 0 .\end{cases}
$$

\subsection{Numerical results}

In order to examine the accuracy of the diffusion approximation, we shall numerically compare the approximate results obtained in Section 3 through 5 with the above analytical results. For computational convenience, consider the standard $E_{k} / M / 1$ system in which the d.f.s $A$ and $A_{0}$ are the common Erlang distribution with phase $k$. The mean first overflow time given by (3.14), (4.3) and (4.9), and its relative errors for the $M / M / 1$ system are shown in Tables 1 and 2 , where the relative error means

$$
\frac{\text { (approximate value) }-(\text { exact value) }}{(\text { exact value })} \times 100(\%)
$$

Tables 3 and 4 show the variance of the first overflow time given by (3.16) and (4.4), and its relative errors for the $M / M / 1$ system. Tables 5 and 6 show the mean and the variance of the first overflow time and their relative errors for the $E_{2} / M / 1$ system and for the $E_{5} / M / 1$ system, respectively. From these tables, it is concluded about the accuracy of the diffusion approximation with respect to the moments that:

i) When the initial value $i$ is close to $N$, all the moments $\mathrm{E}_{\sim}\left[T_{d}(i, N)\right]$ $\mathrm{E}\left[\hat{T}_{d}(i, N)\right], \quad \mathrm{E}\left[\tilde{T}_{d}(i, N)\right], \quad \mathrm{V}\left[T_{d}(i, N)\right]$ and $\mathrm{V}\left[\hat{T}_{d}(i, N)\right]$ become accurate.

ii) For small $k, \mathrm{E}\left[\hat{T}_{d}(i, N)\right]$ is more accurate than $\mathrm{E}\left[\mathrm{T}_{d}(i, N)\right]$. 
iii) For large $k, E\left[T_{d}(i, N)\right]$ is more accurate than $E\left[\hat{T}_{d}(i, N)\right]$ for the case $\rho>1.0$.

iv) The relative errors of $\mathrm{V}\left[T_{d}(i, N)\right]$ and $\mathrm{V}\left[\hat{T}_{d}(i, N)\right]$ are greater than those of $E\left[T_{d}(i, N)\right]$ and $E\left[T_{d}(i, N)\right]$. It should be noted, however, that the relative errors of the corresponding standard deviation are about the same as those of the means.

Tables 1 through 6 are dealt with only the case $\rho=0.95$ and $\rho=1.05$. In order to examine the accuracy of the diffusion approximation for the other value of $\rho$, the mean and the variance of the first overflow time are shown for the $E_{2} / M / 1$ system with $i=0$ in Figure 1 . It follows from Figure 1 that the approximate solutions behave similarly to the exact ones even in the light traffic.

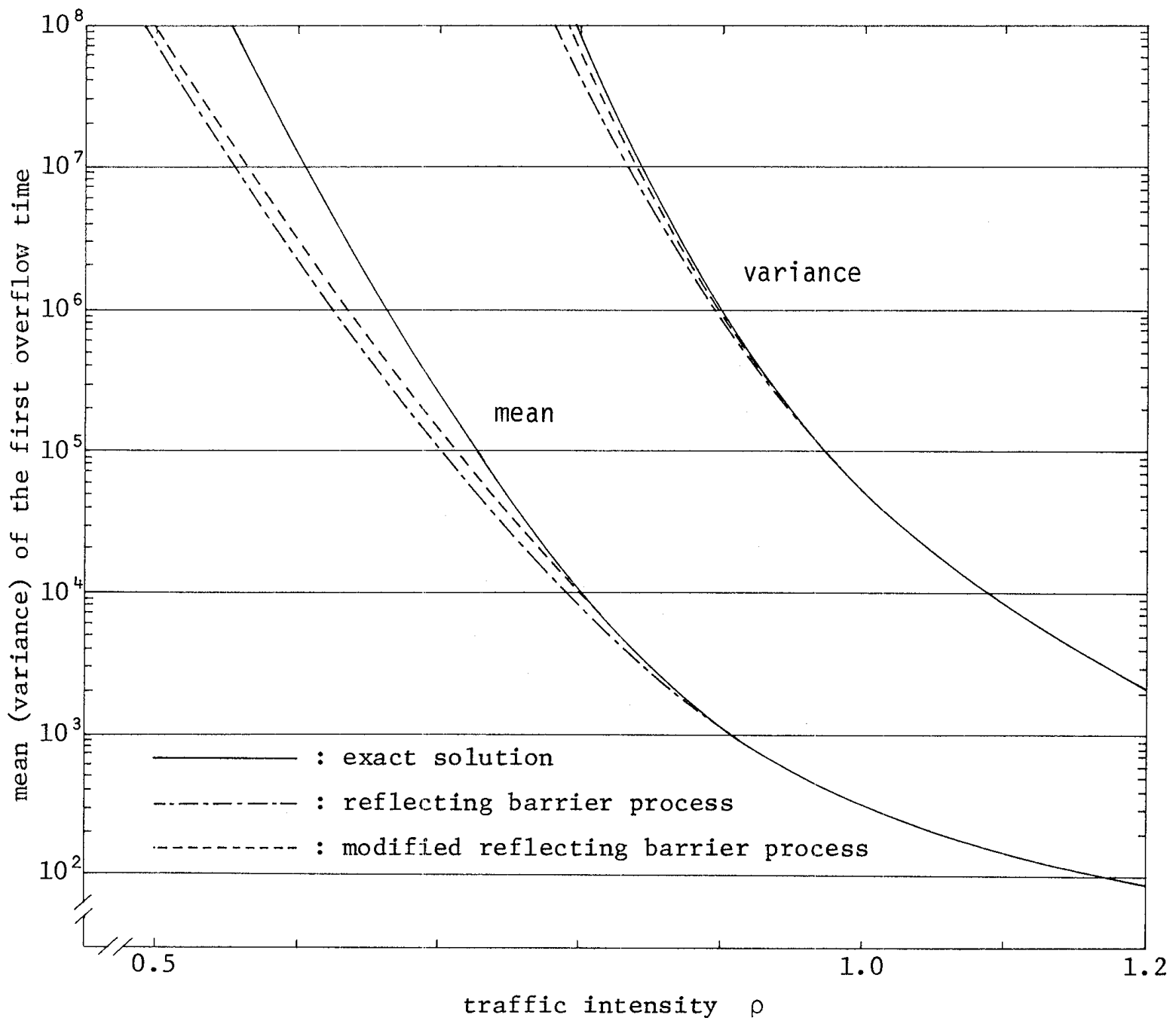

Figure 1. The mean and the variance of the first overflow time for the $E_{2} / M / 1$ system $\left(N=21, i=0, \frac{1}{\mu}=1.0\right)$. 
Furthermore, many other numerical results lead to the following statement:

v) All the moments become accurate for the case $\rho>0.9$.

vi) The relative errors of the moments increase as $N$ decreases. Even in such cases, $\mathrm{E}\left[\hat{T}_{d}(i, N)\right]$ and $\mathrm{E}\left[\tilde{T}_{d}(i, N)\right]$ are quite more accurate than $E\left[T{ }_{d}(i, N)\right]$.

Next, we shall investigate the d.f. of the first overflow time. However, the expressions (1.2), (3.6), (4.2) and (4.6) for the L.S.T. of the d.f. are complicated and their analytical inversions appear to be impossible. Hence, we shall caluculate the d.f.s of the first overflow time by using a routine of numerica1 L.T. inversion. Two different methods are adopted to invert the L.S.T.s, that is, Gaver's method [7] and the method of Bellman, Kalaba and Lockett [1]. The reason for using different methods is due to a mutual check on the agreement of the results, since the performance of a method is highly dependent on the nature of the original function [1]. It follows from the numerical tests that Gaver's method is more accurate than the method of

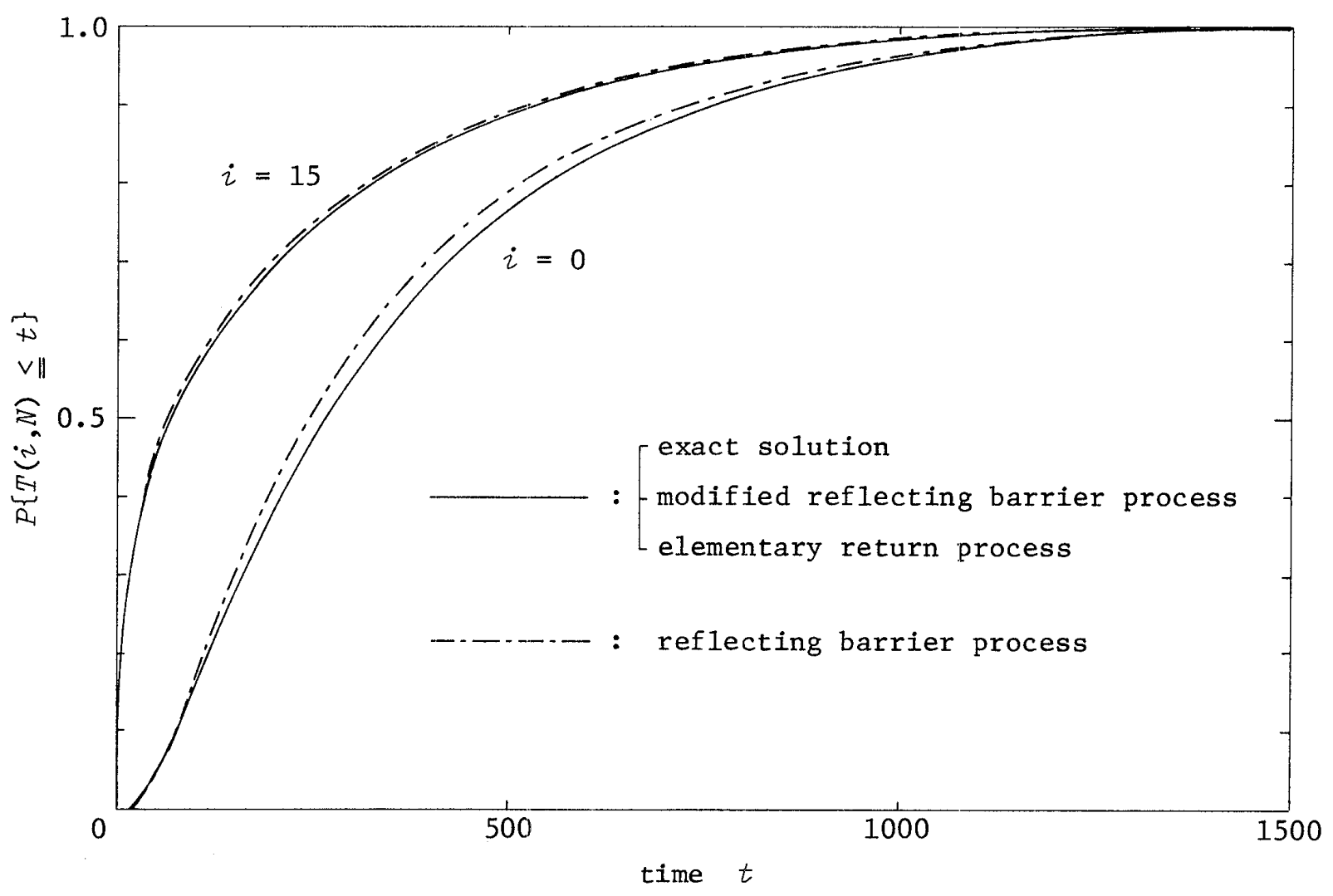

Figure 2. The d.fo of the first overflow time for the $M / M / 1$ system $\left(N=21, \frac{1}{\mu}=1.0, \rho=0.95\right)$. 
Bellman et al.. Therefore, the former is selscted to use in the following, and the latter is used for checking the results. Since the L.S.T. $f_{i N}(s)$ for $k \neq 1$ is derived from a solution of the system of linear equations, the numerical inversion seems to be fairly difficult. Hence, we restrict our caluculations to the case of $k=1$, i.e., the $M / M / 1$ system. Figure 2 illustrates the d.f. of the first overflow time for the case of $N=21, i=$ 0 or 15 , and $\rho=0.95$.

By using the same routine of the L.T. inversion, we shall caluculate the d.f. of the maximum number of customers in the system. Inverting numerically (5.4) and (6.21), we obtain Figure 3 which shows the d.f. of the maximum number of customers in the $M / M / 1$ system at $t=20$ or 40 . The d.f. at any other time can be caluculated in much the same way.

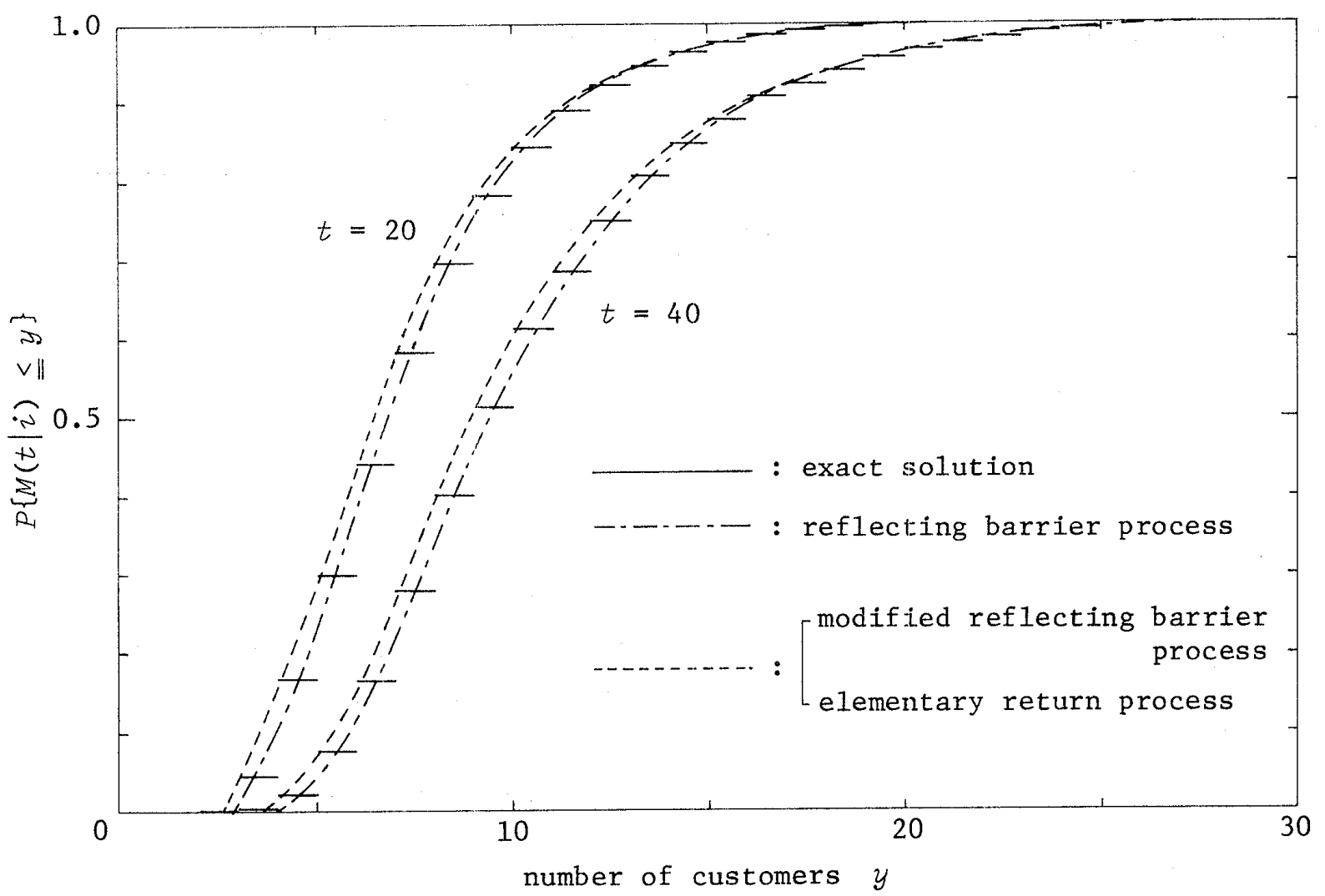

Figure 3. The d.f. of the maximum number of customers in the $M / M / 1$ system $(i=0, \rho=0.95)$. 


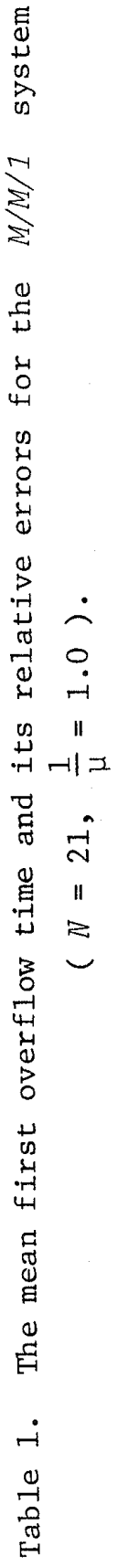

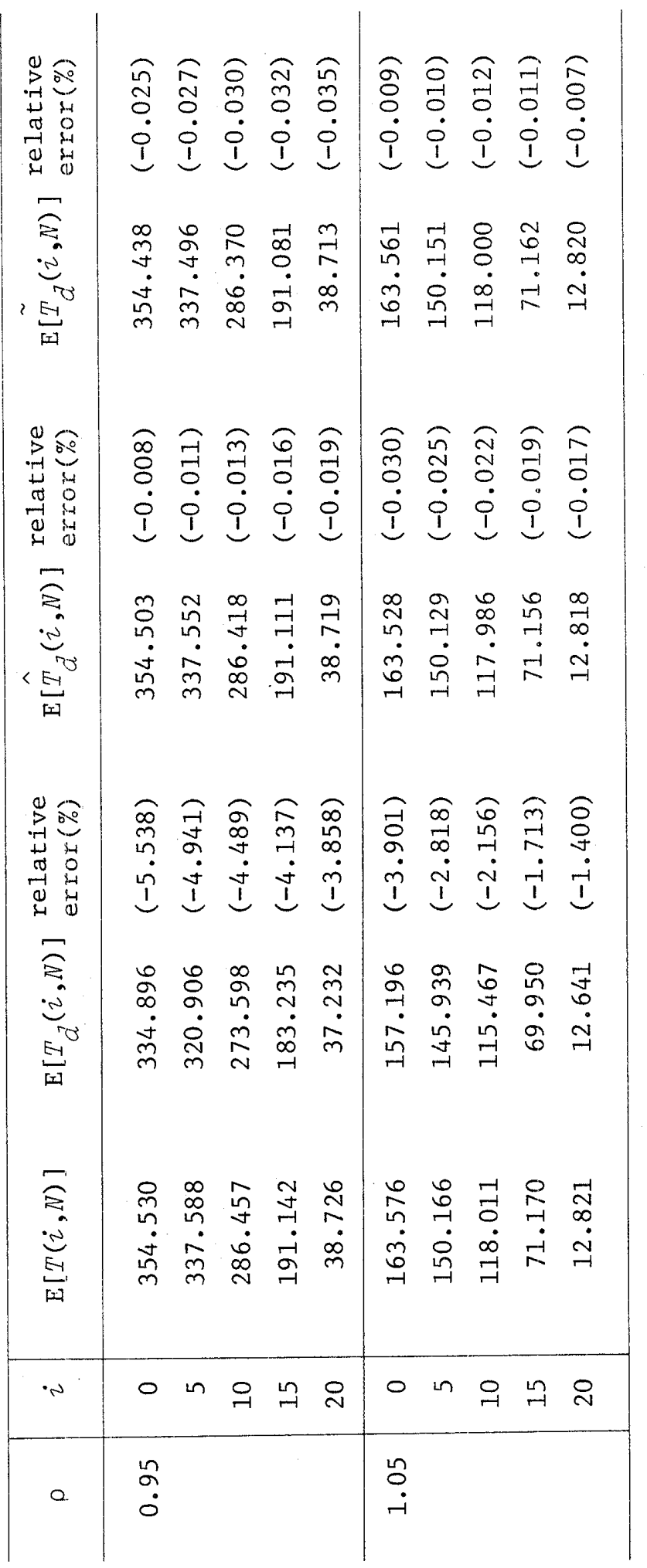




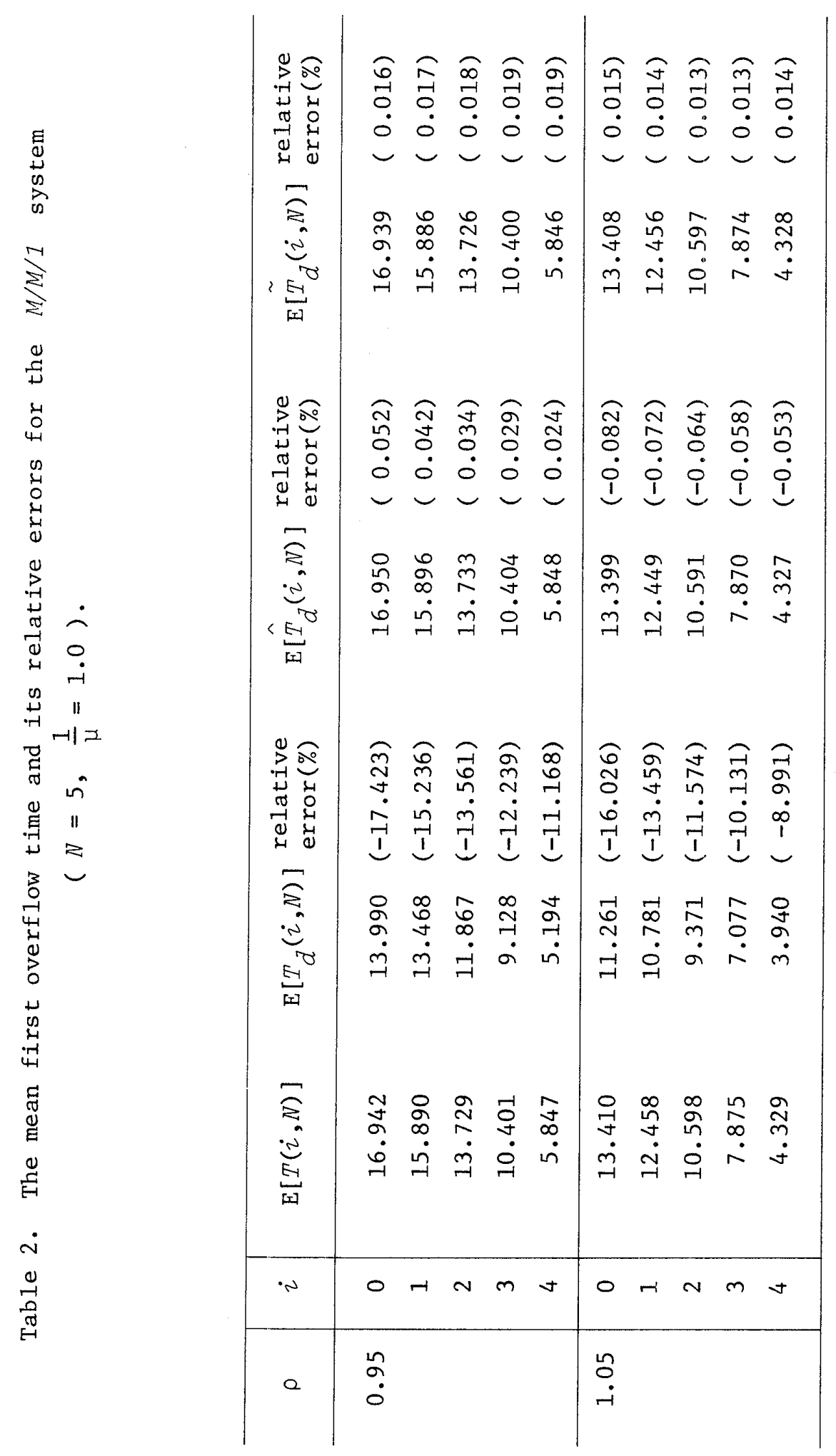


Table 3. The variance of the first overflow time and its relative errors for the $M / M / 1$ system $\left(N=21, \frac{1}{\mu}=1.0\right)$.

\begin{tabular}{|c|c|c|c|c|c|c|}
\hline$\rho$ & $i$ & $\mathrm{~V}[T(i, N)]$ & $\mathrm{V}\left[T_{d}(i, N)\right]$ & $\begin{array}{l}\text { relative } \\
\text { error }(\%)\end{array}$ & $\mathrm{V}\left[\hat{T}_{d}(i, N)\right]$ & $\begin{array}{l}\text { relative } \\
\text { error }(\%)\end{array}$ \\
\hline \multirow[t]{5}{*}{0.95} & 0 & 95996.9 & 85301.1 & $(-11 \cdot 142)$ & 95920.8 & $(-0.079)$ \\
\hline & 5 & 95792.4 & 85166.2 & $(-11.093)$ & 95719.2 & $(-0.077)$ \\
\hline & 10 & 92662.7 & 82625.6 & $(-10.832)$ & 92597.1 & $(-0.071)$ \\
\hline & 15 & 76274.2 & 68409.6 & $(-10 \cdot 311)$ & 76225.1 & $(-0.064)$ \\
\hline & 20 & 20242.8 & 18294.2 & $(-9.626)$ & 20230.6 & $(-0.060)$ \\
\hline \multirow[t]{5}{*}{1.05} & 0 & 15432.8 & 14258.3 & $(-7.610)$ & 15397.6 & $(-0.228)$ \\
\hline & 5 & 15312.9 & 14176.5 & $(-7.421)$ & 15280.1 & $(-0.214)$ \\
\hline & 10 & 14525.0 & 13172.7 & $(-6.765)$ & 14102.1 & $(-0.187)$ \\
\hline & 15 & 10280.7 & 9674.9 & $(-5.893)$ & 10264.4 & $(-0.159)$ \\
\hline & 20 & 2226.5 & 2114.3 & $(-5.039)$ & 2223.5 & $(-0.135)$ \\
\hline
\end{tabular}

Table 4. The variance of the first overflow time and its relative errors for the $M / M / 1$ system $\left(N=5, \frac{1}{\mu}=1.0\right)$.

\begin{tabular}{c|c|ccccc}
\hline$\rho$ & $i$ & $\mathrm{~V}[T(i, N)]$ & $\mathrm{V}\left[T_{d}(i, N)\right] \begin{array}{l}\text { relative } \\
\text { error(\%) }\end{array}$ & $\begin{array}{c}\mathrm{V}\left[\hat{T}_{d}(i, N)\right] \\
\text { relative } \\
\text { error(\%) }\end{array}$ \\
\hline \multirow{2}{*}{0.95} & 0 & 204.446 & 134.941 & $(-33.996)$ & 201.782 & $(-1.303)$ \\
& 1 & 203.338 & 134.759 & $(-33.727)$ & 200.849 & $(-1.224)$ \\
& 2 & 196.336 & 131.895 & $(-33.822)$ & 194.199 & $(-1.088)$ \\
& 3 & 172.983 & 118.862 & $(-31.287)$ & 171.376 & $(-0.929)$ \\
& 4 & 116.004 & 81.950 & $(-29.365)$ & 115.107 & $(-0.774)$ \\
\hline \multirow{7}{*}{1.05} & 0 & 119.891 & 81.797 & $(-31.774)$ & 117.503 & $(-1.992)$ \\
& 1 & 118.984 & 81.644 & $(-31.382)$ & 116.755 & $(-1.873)$ \\
& 2 & 113.798 & 79.448 & $(-30.185)$ & 111.888 & $(-1.679)$ \\
& 3 & 98.151 & 70.356 & $(-28.319)$ & 96.718 & $(-1.460)$ \\
& 4 & 63.613 & 46.994 & $(-26.125)$ & 62.817 & $(-1.252)$ \\
\hline
\end{tabular}


Table 5. The mean and the variance of the first overflow time and their relative errors for the $E_{2} / M / 1$ system $\left(N=21, \frac{1}{\mu}=1.0\right)$.

\begin{tabular}{c|r|rrrrr}
\hline \multirow{2}{*}{0} & $i$ & $E[T(i, N)]$ & $E\left[T_{d}(i, N)\right] \begin{array}{c}\text { relative } \\
\text { error }(\%)\end{array}$ & $\begin{array}{c}E\left[T_{d}(i, N)\right] \\
\text { relative } \\
\text { error }(\%)\end{array}$ \\
\hline \multirow{1}{*}{0.95} & 0 & 530.331 & 510.009 & $(-3.832)$ & 533.957 & $(0.684)$ \\
& 5 & 509.539 & 490.971 & $(-3.644)$ & 511.853 & $(0.454)$ \\
& 10 & 439.555 & 423.899 & $(-3.562)$ & 440.479 & $(0.210)$ \\
& 15 & 300.035 & 289.409 & $(-3.542)$ & 299.951 & $(-0.028)$ \\
& 20 & 62.532 & 62.298 & $(-3.573)$ & 62.366 & $(-0.266)$ \\
\hline \multirow{1}{*}{1.05} & 0 & 193.305 & 191.958 & $(-0.696)$ & 197.497 & $(2.170)$ \\
& 5 & 177.631 & 177.218 & $(-0.232)$ & 180.686 & $(1.720)$ \\
& 10 & 138.698 & 138.645 & $(-0.039)$ & 140.621 & $(1.386)$ \\
& 15 & 82.848 & 82.900 & $(0.063)$ & 83.801 & $(1.150)$ \\
& 20 & 14.767 & 14.784 & $(0.116)$ & 14.911 & $(0.974)$ \\
\hline
\end{tabular}

\begin{tabular}{|c|c|c|c|c|c|c|}
\hline$\rho$ & $i$ & $\mathrm{~V}[T(i, N)]$ & $v\left[T_{d}(i, N)\right]$ & $\begin{array}{l}\text { relative } \\
\text { error }(\%)\end{array}$ & $\mathrm{V}\left[\hat{T}_{d}(i, N)\right]$ & $\begin{array}{l}\text { relative } \\
\text { error }(\%)\end{array}$ \\
\hline \multirow[t]{5}{*}{0.95} & 0 & 220291.4 & 205129.2 & $(-6.842)$ & 225603.2 & $(2.411)$ \\
\hline & 5 & 220008.5 & 204966.7 & $(-6.837)$ & 225258.8 & $(2.386)$ \\
\hline & 10 & 214458.3 & 199832.3 & $(-6.820)$ & 219222.8 & $(2.222)$ \\
\hline & 15 & 180776.3 & 168452.2 & $(-6.817)$ & 184080.7 & $(1.828)$ \\
\hline & 20 & 50210.5 & 46759.4 & $(-6.873)$ & 50822.2 & $(1.218)$ \\
\hline \multirow[t]{5}{*}{1.05} & 0 & 19998.4 & 20176.3 & $(0.890)$ & 21298.7 & $(6.502)$ \\
\hline & 5 & 19853.5 & 20037.8 & $(0.928)$ & 21117.2 & $(6.365)$ \\
\hline & 10 & 18258.0 & 18446.1 & $(1.030)$ & 19330.0 & $(5.871)$ \\
\hline & 15 & 13125.2 & 13272.3 & $(1.121)$ & 13810.0 & $(5.217)$ \\
\hline & 20 & 2786.2 & 2818.7 & $(1.168)$ & 2913.6 & $(4.574)$ \\
\hline
\end{tabular}


Table 6. The mean and the variance of the first overflow time and their relative errors for the $E_{5} / M / 1$ system $\left(N=21, \frac{1}{\mu}=1.0\right)$.

\begin{tabular}{c|r|rrrrr}
\hline \multirow{2}{*}{$\rho$} & $i$ & $E[T(i, N)]$ & $E\left[T_{d}(i, N)\right] \begin{array}{l}\text { relative } \\
\text { error(\%) }\end{array}$ & $\begin{array}{c}\left.\hat{E}_{\hat{T}}(i, N)\right] \\
\text { relative } \\
\text { error(\%) }\end{array}$ \\
\hline \multirow{2}{*}{0.95} & 0 & 759.051 & 731.885 & $(-3.579)$ & 761.293 & $(0.295)$ \\
& 5 & 734.219 & 707.597 & $(-3.626)$ & 733.832 & $(-0.053)$ \\
& 10 & 642.784 & 618.404 & $(-3.793)$ & 639.809 & $(-0.463)$ \\
& 15 & 448.527 & 430.411 & $(-4.039)$ & 444.464 & $(-0.906)$ \\
& 20 & 96.220 & 92.024 & $(-4.361)$ & 94.884 & $(-1.389)$ \\
\hline \multirow{7}{*}{1.05} & 0 & 217.732 & 220.665 & $(1.347)$ & 225.547 & $(3.589)$ \\
& 5 & 199.924 & 202.579 & $(1.328)$ & 205.454 & $(2.776)$ \\
& 10 & 154.949 & 156.766 & $(1.173)$ & 158.314 & $(2.172)$ \\
& 15 & 91.671 & 92.611 & $(1.025)$ & 93.282 & $(1.757)$ \\
& 20 & 16.179 & 16.324 & $(0.893)$ & 1.6 .414 & $(1.450)$ \\
\hline
\end{tabular}

\begin{tabular}{c|r|rrrrr}
\hline \multicolumn{1}{c}{$\rho$} & $i$ & $\mathrm{~V}[T(i, N)]$ & $\mathrm{V}\left[T_{d}(i, N)\right] \begin{array}{c}\text { relative } \\
\text { error(\%) }\end{array}$ & $\begin{array}{c}\hat{\mathrm{V}}\left[\hat{T}_{d}(i, N)\right] \\
\text { relative } \\
\text { error(\%) }\end{array}$ \\
\hline \multirow{2}{*}{0.95} & 0 & 464572.9 & 436804.8 & $(-5.977)$ & 473805.2 & $(1.987)$ \\
& 5 & 464188.3 & 436389.6 & $(-5.989)$ & 473269.7 & $(1.956)$ \\
& 10 & 455003.3 & 427268.8 & $(-6.095)$ & 462831.0 & $(1.720)$ \\
& 15 & 391467.7 & 366298.5 & $(-6.429)$ & 395688.9 & $(1.078)$ \\
& 20 & 113583.5 & 105549.8 & $(-7.073)$ & 113555.0 & $(-0.025)$ \\
\hline \multirow{7}{*}{1.05} & 0 & 237062.9 & 252597.4 & $(6.553)$ & 263078.8 & $(10.974)$ \\
& 5 & 235246.8 & 250536.5 & $(6.454)$ & 260525.5 & $(10.699)$ \\
& 10 & 215317.5 & 228345.3 & $(6.050)$ & 236268.7 & $(9.730)$ \\
& 15 & 152590.5 & 160948.0 & $(5.477)$ & 165554.8 & $(8.496)$ \\
& 20 & 31716.0 & 33263.4 & $(4.879)$ & 34036.8 & $(7.317)$ \\
\hline
\end{tabular}


7. Concluding Remarks

By using diffusion approximation, we have investigated some basic properties of the first overflow time in a general queueing system. The d.f. and the first two moments of the first overflow time have been derived in the L.S.T. and explicit forms, respectively. For the case of Poisson arrival and/or small $N$, these results have been corrected by modifying the boundary condition at the origin. It is noted that under the heavy traffic condition, the solutions by diffusion approximation converge to those by fluid approximation. These results have been applied to the analysis of the maximum number of customers in the $G I / G / I(\infty)$ queueing system. The L.S.T. of its d.f. and the L.T. of its mean have been derived. It is shown from numerical results that they are fairly accurate in the heavy traffic.

It is of interest to extend the model to many server queueing system. It seems that the extension is not so difficult theoretically, since for many server system, it is only necessary to vary the diffusion parameters $a$ and $b$ appropriately [15]. It becomes, however, difficult to solve explicitly the corresponding differential equations because of spatial nonhomogeneity.

\section{Acknowledgment}

The authors would like to thank the referees for several valuable suggestions and clarifications.

\section{Appendix}

Derivation of (3.14)

Let $\bar{m}_{1}\left(x_{0}\right)$ denote a solution of the homogeneous differential equation

$$
\frac{1}{2} a \frac{d^{2} m_{1}}{d x_{0}^{2}}+b \frac{d m_{1}}{d x_{0}}=0 \text {. }
$$

When $b \neq 0$, by the usual quadrature we obtain

$$
\bar{m}_{1}\left(x_{0}\right)=A_{1}+B_{1} \exp \left(-2 b x_{0} / a\right) \text {, }
$$

where $A_{1}$ and $B_{1}$ are arbitary constants. Upon choosing $m_{1}\left(x_{0}\right)=-x_{0} / b$ as a particular solution of (3.11) for $n=1$, a general solution of (3.11) is given by

$$
m_{1}\left(x_{0}\right)=A_{1}+B_{1} \exp \left(-2 b x_{0} / a\right)-\frac{1}{b} x_{0} .
$$

Applying the boundary condition (3.12) to (A.3), we have 
$(\mathrm{A} .4)$

$$
B_{1}=-a / 2 b^{2} \text {. }
$$

Substituting (A.4) in (A.3) and the boundary condition (3.13) lead to

$$
A_{1}=\frac{1}{b}\left\{\frac{a}{2 b} \exp (-2 b N / a)+N\right\} \text {. }
$$

From (A.3), (A.4) and (A.5), we obtain the desired result for $b \neq 0$.

When $b=0$ in (A.1), it follows easily that

$$
m_{1}\left(x_{0}\right)=-\frac{1}{a} x_{0}^{2}+C_{1} x_{0}+D_{1} \text {, }
$$

where $C_{1}$ and $D_{1}$ are arbitary constants. Applying the boundary conditions (3.12) and (3.13) to (A.6) yields $C_{1}=0$ and $D_{1}=N^{2} / a$, and hence we obtain (3.14) for $b=0 . \square$

Derivation of (3.15)

Let $\bar{m}_{2}\left(x_{0}\right)$ denote a homogeneous solution of (3.11) for $n=2$. When $b \neq 0$, it is clear that $\bar{m}_{2}\left(x_{0}\right)$ has the same form as (A.2), that is,

$$
\bar{m}_{2}\left(x_{0}\right)=A_{2}+B_{2} \exp \left(-2 b x_{0} / a\right) \text {, }
$$

where $A_{2}$ and $B_{2}$ are arbitary constants. Assume the form of a particular solution of (3.11) for $n=2$ as

$$
m_{2}\left(x_{0}\right)=p x_{0}^{2}+q x_{0}+r x_{0} \exp \left(-2 b x_{0} / a\right),
$$

where $p, q$ and $r$ are arbitary constants. Substituting (A.8) and (3.14) in

$$
\frac{1}{2} a \frac{d^{2} m_{2}}{d x_{0}^{2}}+b \frac{d m_{2}}{d x_{0}}=-2 m_{1}\left(x_{0}\right)
$$

and comparing the coefficients of each term of $x_{0}$ in both sides, we have

$$
p=1 / b^{2}
$$

$$
\begin{aligned}
& q=-a\{1+\exp (-2 b N / a)\} / b^{3}-2 N / b^{2} \\
& r=-a / b^{3} .
\end{aligned}
$$

Hence, a general solution of (A.9) is given by

$$
\begin{aligned}
m_{2}\left(x_{0}\right)=A_{2} & +B_{2} \exp \left(-2 b x_{0} / a\right)-\frac{1}{b^{2}} x_{0}\left(\left(2 N-x_{0}\right)\right. \\
& \left.+\frac{a}{b}\left\{1+\exp (-2 b N / a)+\exp \left(-2 b x_{0} / a\right)\right\}\right) .
\end{aligned}
$$

Applying the boundary condition (3.12) to (A.11), we have

$$
B_{2}=-\frac{a}{b^{3}}\left(N+\frac{a}{2 b}\{2+\exp (-2 b N / a)\}\right) \text {. }
$$

Substitution of (A.12) in (A.11) and the boundary condition (3.13) lead to

$$
A_{2}=\frac{a}{b} 3\left(3 N+\frac{a}{2 b}\{2+\exp (-2 b N / a)\}\right) \exp (-2 b N / a)+\frac{N^{2}}{b^{2}}+\frac{a N}{b^{3}} .
$$

From (A.11), (A.12) and (A.13), we obtain the desired result for $b \neq 0$. When $b=0$ in (A.9), it follows easily that 
(A. 14)

$$
m_{2}\left(x_{0}\right)=\frac{1}{3 a^{2}} x_{0}^{4}-\frac{2}{a^{2}} N^{2} x_{0}^{2}+C_{2} x_{0}+D_{2},
$$

where $C_{2}$ and $D_{2}$ are arbitary constants. Applying the boundary conditions (3.12) and (3.13) to (A.14) yields $C_{2}=0$ and $D_{2}=5 N^{4} / 3 a^{2}$, and hence we obtain (3.15) for $b=0 . \square$

Derivation of (4.9)

When $b \neq 0$, for $n=1$ the general solution of (3.11) has the following form given by (A.3):

$$
\tilde{m}_{1}\left(x_{0}\right)=A_{3}+B_{3} \exp \left(-2 b x_{0} / a\right)-\frac{1}{b} x_{0},
$$

where $A_{3}$ and $B_{3}$ are arbitary constants. Applying the boundary condition (4.8) to (A.15), we have

$$
\text { (A.16) } \quad B_{3}=\frac{1}{1-\exp (-2 b / a)}\left(\frac{1}{\lambda}-\frac{1}{b}\right) \text {. }
$$

Substitution of (A.16) into (A.15) and the boundary condition (3.13) lead to

$$
A_{3}=\frac{N}{b}-\frac{1}{1-\exp (-2 b / a)}\left(\frac{1}{\lambda}-\frac{1}{b}\right) \exp (-2 b N / \alpha) \text {. }
$$

From (A.15), (A.16) and (A.17), we obtain the desired result for $b \neq 0$. When $b=0$, it follows from $\left(A_{0} 6\right)$ that $m_{1}\left(x_{0}\right)$ has the form:

$$
\tilde{m}_{1}\left(x_{0}\right)=-\frac{1}{a} x_{0}^{2}+C_{3} x_{0}+D_{3} \text {, }
$$

where $C_{3}$ and $D_{3}$ are arbitary constants. Applying the boundary conditions (4.8) and (3.13) to (A.18) yields $C_{3}=1 / a-1 / \lambda$ and $D_{3}=N\{(N-1) / a+$ $1 / \lambda\}$. Hence we obtain (4.9) for $b=0$ from the relations $b=\lambda-\mu$ and $\rho=\lambda / \mu \cdot \square$

\section{References}

[1] Bellman, R. E., Kalaba, R. E. and Lockett, J. A., Numerical Inversion of the Laplace Transform, American Elsevier, New York, 1966.

[2] Cohen, J. W., The Singte Server Queue, North-Holland, Amsterdam, 1969. , "On the Busy Periods for the $M / G / 1$ Queue with Finite and Infinite Waiting Room," Journal of Applied Probability, 8, 821-827 (1971).

[4] Cox, D. R. and Miller, H. D., The Theory of Stochastic Processes, John Wiley, New York, 1965.

[5] Feller, W., "Diffusion Processes in One Dimension," Transactions of the American Mathematical Society, 77, 1-31 (1954). 
[6] Finch, P. D., "The Effect of the Size of the Waiting Room on a Simple Queue," Journal of the Royal Statistical Society, Series B, 20, 182-186 (1958).

[7] Gaver, D. P., Jr., "Observing Stochastic Processes, and Approximate Transform Inversion," Operations Research, 14, 444-459 (1966)。

[8] Heyman, D. P., "A Diffusion Model Approximation for the GI/G/1 Queue in Heavy Traffic," The Beil System Technical Journal, 54, 1637-1646 (1975)。

[9] Hokstad, P., "Asymptotic Behaviour of the $E_{k} / G / I$ Queue with Finite Waiting Room," Joumal of Applied Probability, 14, 358-366 (1977).

[10] Keilson, J., "The Ergodic Queue Length Distribution for Queueing System with Finite Capacity," Journal of the Royal Statistical Society, Series $B, 28,190-201$ (1966).

[11] Kleinrock, L., Queueing Systems, Vol. II: Computer Applications, WileyInterscience, New York, 1975.

[12] Newell, G. F., Applications of Queueing Theory, Chapman \& Hall, Ltd., London, 1971.

[13] Ross, S. M., Applied Probability Models with Optimization Applications, Holden-Day, San Francisico, 1969.

[14] Saaty, T. L., "Some Stochastic Processes with Absorbing Barriers," Journal of the Royal Statistical Society, Series B, 23, 319-334 (1961).

[15] Sunaga, T., Kondo, E. and Biswas, S. K., "An Approximation Method Using Continuous Models for Queueing Problems," Journat of the Operations Research Society of Japan, 21, 29-44 (1978).

[16] Suzuki, T. and Hayashi, K., "On Queue Disciplines," ibid., 13, 43-58 (1970).

[17] Sweet, A. L. and Hardin, J. C., "Solutions for Some Diffusion Processes with Two Barriers," Joumal of Applied Probability, 7, 423-431 (1970).

[18] Truslove, A. L., "Queue Length for the $E_{k} / G / 1$ Queve with Finite Waiting Room," Advances in Applied Probability, 7, 215-22.6 (1975).

[19] _. "The Busy Period of the $E_{k} / G / 1$ Queue with Finite Waiting Room," ibid., 7, 416-430 (1975).

Toshikazu KIMURA: Department of Applied Mathematics and Physics, Faculty of Engineering, Kyoto University, Yoshida-Honmachi, Sakyo-Ku, Kyoto 606, Japan. 
有限の待ち合い室を有する $\mathrm{GI} / \mathrm{G} / \mathrm{I}$ 待ち行列ンステムに 対する拡散近似：I-ファーストオーバーフロー・タイム

$\begin{array}{ccccc}\text { 京都大学 } & \text { 木 } & \text { 村 } & \text { 俊 } & \text { 一 } \\ \text { 大 } & \text { 野 } & \text { 勝 } & \text { 久 } \\ & \text { 三 } & \text { 根 } & & \text { 久 }\end{array}$

有限の待ち合い室を持つ待ち行列系を考えよう。この待ち合い室が一杯であるときに到着した客は， 系内に入ることを許されないあのとする。この現象は客のオーバーフローと呼ばれ，“良質のサービ ス”という観点からあ，“損得勘定”という観点からも，極力避けることが望ましい現象である。こ のオーバーフローに対して，サービス開始後初めてオーバーフローが起こるまでの時間を first overflow time と呼ぶことにする。すなわち, 系内に許される最大客数を（N-1)人, サービ 又開始時に i 人の客がいる場合の first overflow t ime は次のように定義される。

$$
\mathrm{T}(\mathrm{i}, \mathrm{N})=\mathrm{inf}\{\mathrm{t} \geqq 0 \mid \mathrm{Q}(\mathrm{t})=\mathrm{N}, \mathrm{Q}(0)=\mathrm{i}\}, \quad \mathrm{N} \geqq 2,0 \leqq \mathrm{i} \leqq \mathrm{N}-1 .
$$

ここで， $\mathrm{Q}(\mathrm{t})$ は時刻 $\mathrm{t}$ 亿括ける系内客数を表わしている。 $\mathrm{M} / \mathrm{M} / 1$ 系に対しては, 原点に反射壁, N飞吸収壁を有する出生死隇過程の, 吸収壁への first passage timeがfirst overflow time飞対応し, Saaty（１９６１１）によって既に解析 されている。本論文では $\mathrm{GI} / \mathrm{G} / 1$ 系に対するfirst overflow timeを拡散近似の手法を用 いて近似的に解析する。すなわち， $Q(t)$ を近似する拡散過程を $\mathrm{X}(\mathrm{t})$ とするとき，

$$
\mathrm{T}_{\mathrm{d}}(\mathrm{i}, \mathrm{N})=\inf \{\mathrm{t} \geqq 0 \mid \mathrm{X}(\mathrm{t})=\mathrm{N}, \mathrm{X}(0)=\mathrm{i}\}, \quad 0 \leqq \mathrm{i}<\mathrm{N},
$$

によってT(i，N) を近似するのである。拡散近似はheavy traffic 時にかなり有効であると予 想される。またオーバーフローは主として heavy traffic 時に考虑されるべき現象であるから， 系はheavy traffic の状態にあると仮定している。この仮定の下で，原点に招ける境界条件とし て反射壁を持つ拡散過程を用いて， $\mathrm{T}_{\mathrm{d}}(\mathrm{i}, \mathrm{N})$ の分布及びそのモーメントを導出する。 $\mathrm{Q}(\mathrm{t})$ は央 際には原点に执いて零でないある有限の時間停まっているから，この滞在時間を考慮した補正を次に 考える。特に，Nの值が小さい場合，もしくは到着がポアソン過程に従っている場合には，補正解が 先に得られた解よりも，かなり正確であることが示される。

以上の拡散近似解の精度を評価するために，GI/M/l 系に対してfirst overflow time の㛜密解を同時に求めている。この厳密解と近似解を数值的に比較して, 仮定した heavy traffic の状況では近似解は非常に正確であることが示される。 